\title{
Fractures and Biomechanical Characteristics of the Bone
}

\author{
Tomaz Velnar1,2, Gorazd Bunc ${ }^{1}$, Lidija Gradisnik ${ }^{3}$ \\ ${ }^{1}$ Department of Neurosurgery, University Medical Centre Maribor, Maribor, Slovenia \\ ${ }^{2}$ Department of Traumatology, University Medical Centre Ljubljana, Ljubljana, Slovenia \\ ${ }^{3}$ Laboratory Centre, Medical Faculty Maribor, Maribor, Slovenia \\ Email: tvelnar@hotmail.com
}

Received 1 May 2015; accepted 27 June 2015; published 30 June 2015

Copyright (C) 2015 by authors and Scientific Research Publishing Inc.

This work is licensed under the Creative Commons Attribution International License (CC BY).

http://creativecommons.org/licenses/by/4.0/

(c) (i) Open Access

\section{Abstract}

The biological tissue is affected by external and internal deformation forces: tractive/tensile forces, shearing and compressive forces. The bone is deformed under the effect of a force. If the load exceeds the bone solidity limitation, fracture occurs. A mature bone consists of compact and spongy bone tissue. The basic structural unit of the cortical bone tissue are osteons and spongiosa consists of a network of bone trabeculae. The organic and mineral parts of the bone are responsible for the special bone characteristics. The effect of a physical activity on the mechanical characteristics of the bone is associated with the intensity of the load. Fractures are more common in elderly people as the bone structure is altered on account of osteoporosis and contains less bone tissue. Biomechanical characteristics with anatomic and histological bone structure as well as osteoporotic hip fractures are described in the paper.

\section{Keywords}

Fracture, Biomechanical Characteristics, Bone, Structure, Surgery

\section{Introduction}

Biological tissues are daily subjected to different deformation forces. These forces can be internal, as in muscular contraction, or external, when forces affect the body [1]. The basis of studying the mechanical characteristics of live material is the concept of mechanical load: tractive/tensile forces, shearing forces and compressive forces. The first ones describe the extent of object deformation. The object can be subjected only to tractive/tensile forces, which cause changes to its length, or shearing forces, which also bend the object. We use shearing forces to describe the size of angular changes made to the object. Compressive forces are defined as a force per surface 
unit, which act on the object as a result of external load. As in the case of traction, compression loads are also joined with torsion or shearing loads [1]-[3].

The effect of the force on the bone is deformation. If the extent of deformation is not too large, the bone can resume its initial position. In such case, the bone acts as an elastic body. If the force does exceed the critical point, plastic deformation occurs when the bone breaks. The force causing the deformation can be a single action or the deformation is the result of multiple actions and sum of smaller subcritical loads. When the load exceeds the critical point of bone strength, the material gives in and leads to bone fracture [2] [4].

\section{Bone Tissue Structure and Its Physical Characteristics}

A mature bone consists of two types of tissue components, compact or cortical and spongy or trabecular bone tissue [5] [6]. These two types of bone tissue are categorized on the basis of porosity level and microstructural unit of individual bone tissue type. The cortical bone is primarily located at diaphyses of long bones and forms the external shield or layer, which surrounds the spongy bone around the joints and in vertebrae. The cortical bone is much denser compared to the spongy bone with porosity level between $5 \%$ and $10 \%$. The spongy bone is very porous, with porosity level between $50 \%$ and $90 \%$. It is located at the endpoints of long bones, in vertebral bodies and flat bones. The basic structural unit of cortical bone tissue are osteons, whereas the spongiosa consists of network of trabeculae. Each of these tissues consists of collagen and hydroxyapatite [6]-[8]. The share of organic matter in the bone is $40 \%$, inorganic matter $45 \%$ and cells $15 \%$ [6]. The organization of organic polymer and mineral mass in the bone is responsible for the special bone characteristics. It is typical for collagen fibres to have low elasticity module and therefore respond to loads with good tractive solidity and poor resistance to compressive forces [2] [3]. The bone tissue component consisting of calcium phosphate is solid, noncompressible/incompressible, but brittle and responds well to compression forces. The result of such structure is that bone material is resistant to all three tapes of forces affecting it: tractive, shearing and compression forces. A living bone in the organism is rarely exposed to only one type of force or the bone is rarely affected in one direction only. It is usually subjected to several forces in different directions [4]-[6] [9] [10].

\subsection{Compact Bone Tissue}

Compact bone tissue accounts for $80 \%$ of bone mass [6] [9]. Its basic unit is the osteon. Each osteon consists of concentric layers, or $3 \mu \mathrm{m}$ to $7 \mu \mathrm{m}$ thick lamellae, of compact bone tissue that surround a central canal. The osteocyte is found in ellipsoid lacunae lying in or between the lamellae. Osteocytes are networked to each other via long cytoplasmic extensions that occupy tiny canals called canaliculi. These canals are used for communication on areas of deformation and coordinating bone adaptation to loads [6] [8] [11] [12]. Osteons differ according to their development. Primary osteons developed through mineralization of cartilage tissue, i.e. in areas where bone tissue was not previously present. They contain less lamellae than secondary osteons. They have smaller blood canals than secondary osteons and are supposed to be mechanically stronger. Secondary osteons develop with the exchange of the existing bone tissue. A secondary bone is the result of bone tissue remodelling. During this process the osteoclasts resorb a part of the bone in a shape of a canal, osteoblasts then form a new bone tissue [13] [14]. When the osteoblasts surrounds themselves with the bone matrix, the matrix mineralizes and the osteoblasts become less active and are now called osteocytes. The central part of the canal measuring between $50 \mu \mathrm{m}$ and $90 \mu \mathrm{m}$ remains free and is called the Haversian canal, which contains a blood vessel supplying nutrients to osteocytes in the bone tissue, nerve fibres and osteoblasts. The diameter of secondary osteons is between $0.2 \mu \mathrm{m}$ and $0.3 \mu \mathrm{m}$ [10]-[14].

Bone lamellae consist of collagen type 1 and minerals deposited in collagen fibres. Collagen fibres have in individual lamellae a certain orientation and are in parallel position. Arrangement of fibres between neighbouring lamellae differs up to 90 degrees and based on these lamellar substructures we differentiate osteons type $\mathrm{T}$ (collagen fibres are perpendicular to longitudinal axis of the osteon), type A (collagen fibres are oriented differently) and type L (fibres are parallel with the osteon axis), which under microscope refract the polarized light differently [9] [12].

\subsection{Spongy Bone Tissue}

These types of bones consist of bone trabeculae from collagen and minerals. The length of trabeculae is around 
$1000 \mu \mathrm{m}$ and thickness $0.2 \mu \mathrm{m}$. It has no definite bone structure as in cortical bone tissue. Contrary to the osteons, trabeculae do not have the central canal with a blood vessel. Its task is to absorb and transfer energy from joints. When under the effect of a force it gives in more than the cortical bone tissue and thus neutralizes the force on the bone. Trabecular bone tissue represents $20 \%$ of bone mass. Due to its trabecular structure it has a much larger surface than a compact bone [6] [8] [12].

\section{Bone Tissue Characteristics}

An important advantage of bone tissue is its ability to self-regeneration and therefore cannot be treated as a rigid material but rather as a dynamic system, which is constantly changing its structure [4] [5]. The bone has the ability to regenerate after an injury, to heal as all tissues in the organism, as well as reform or remodel to better resist the mechanical load. This characteristic of bone tissue is described by the Wolff's law. The distribution of forces on bones and their intensity can be modulated by surrounding muscles which contract to decrease or even neutralize the tensile forces on bones and consequently affect the biodynamics. A mature bone has a certain range of deformation within which is still remains elastic after force application. The bone is the most resistant to compression load and the least to shear load [6] [10]. Compared to a compact bone, a spongy bone tissue has the ability to deform five times more but only has $5 \%$ to $10 \%$ of compact bone solidity. The chemical structure of bones largely influences the resistance to forces: deproteinized bone is solid but fragile and non-resistant to tensile load. A demineralized bone is soft and resistant only to tensile forces [8] [10] [11] [13].

The solidity of an individual bone depends on its shape, density, place of force application and speed of force [1] [3]. If a force is applied for a short period of time, the bone will respond to it by increasing its solidity. The final goal of this adjustment is that the bone becomes more resistant to tension and as a result will be able to absorb more energy before it will give in. Therefore fractures become comminuted after a sudden increase in force because the force will accumulate within the bone before the bone will give in. Besides the bones' ability to self-regenerate, the bone may also give in. Fractures may result if the material wears out and the frequency of the load exceeds the time frame necessary for bone regeneration and its adjustment to forces [4] [10] [11] [13].

The effect of physical activity on mechanical characteristics of bones is associated with the intensity of the load, i.e. physical activity. Bone density and bone length change depending on the age of the subject. During the growth period low intensity loads accelerate bone growth and high intensity loads inhibit it. Once the growth is completed, only bone density can change [2] [14] [15]. In low intensity exercises, nothing or little may change. Bone density, however may increase in high intensity loads during intense workout. In absence of physical activity, bone mass and circumference decrease. Loss of bone tissue is documented on X-ray images in patients with poliomyelitis, paraplegia, and muscular dystrophy or after a longer immobilization. Changes in the human bone due to aging are similar to those resulting from low intensity load applied on the bone. In elderly, the loss of calcium leads to the loss of bone mass [16]-[18].

Change in bone mass as a result of decreased or increased physical activity, immobilization or aging finally affects the bone solidity [19]. Bone resistance to the application of compressive forces is proportional to its density and mass. A decrease in bone mass negatively affects the elasticity and resistance to compressive forces. Therefore fractures in older patients where bones changed due to osteoporosis, are of low-energy (non-comminuted), as there is less bone tissue absorbing the energy of loads and resisting it [8] [11] [13].

Surgical treatment of bones with the use of internal fixation also weakens the vertical axis, which can absorb less energy before it gives in with accompanying changes present also in mineral distribution in the bone. Sometimes these modifications are so expressed that it is necessary to remove the fixation material. The bone is enabled to regenerate and acquire its initial strength [5] [17] [18] [20].

\section{Bone Trauma-Clinical Association}

Damages of the locomotor apparatus are among the most common causes of morbidity and mortality. Bone healing is a complicated process with numerous factors involved and the objective is to re-establish the bone tissue function. Biological factors and the mechanics of the organism affect the course of healing. The first component is defined with the vascular supply of tissue and with local as well as systemic regulatory factors, such a cytokines and growth factors whereas the other component is defined with local loads applied on the bone tissue during a fracture, size, and shifts of bone fragments [17] [21]. At a microscopic level, this component is defined with the activity of osteoblasts, osteocytes, and osteoclasts detecting mechanical signals and ex- 
pressing biological markers which affect the process of healing [21] [22].

\subsection{Fractures and Their Categorisation}

Fracture is a partial or complete interruption of the bone tissue continuity. It results form a direct or indirect force application on the bone, which exceeds the bone tissue elasticity [23]-[27]. If the bone has a normal structure, the fracture is a result of a major force application (traumatic fracture). If a bone is disease-changed, a fracture occurs already at a minor force application (pathological fracture). In case of direct force application, a fracture occurs at the spot of force application, whereas in case of indirect force application a shift along the bone occurs and the bone breaks at the spot of the weakest resistance [23] [25] [27].

\subsection{Types of Fractures}

Fracture can be closed or open. In the former, there is no connection of the injured bone with the external environment; it may only lead to broken skin surface. In the latter the the injuries on the skin surface and subcutaneous tissue are connected with the fracture and such types of fracture communicate with the external environment. They are called complicated fractures on account of the existing risk for infection of the bone and the wound [23] [24] [27].

The fracture of the bone tissue may differ. Incomplete interruption causes a break or fissure. In a complete interruption two or more fragments occur. They are either in contact or there is a minor or major dislocation between them. The force applied on the bone may cause also a shift of the fragments. A primary shift is the result of a direct injury and depends on the bone tissue composition, mechanisms of the injury and its intensity. A secondary shift appears after force application due to poor immobilization or muscle pull. The result of fragment shift is deformation or bone shortage [23]-[25].

Spongy bones may compress due to force application. The result is a compressive fracture, e.g. it compresses two vertebrae. Impact fractures result from the application of force which pushes the more solid part of the bone into the softer one. Both fragments are firmly stuck [23] [24]. The cortical bone can break spirally or transversely, depending of the direction of force application. If a direct force application results in several bone segments, it is called as comminuted fracture, which is often accompanied by injuries of the surrounding soft tissues. Fractures are also categorized according to their location on the bone. On long bones, we distinguish between epiphyseal, diaphyseal and metaphyseal fractures, which is important for subsequent healing process [25] [26] [28].

\subsection{Clinical Picture}

Diagnosing a fracture is based on the medical history and examination. The affected extremities or part of body must be thoroughly examined, as well as their position, status of skin, soft tissue, circulation and nerves under the affected segment. When an extremity is at risk due to neurocirculatory defect, an immediate response is needed. In cases of suspected fracture it is obligatory to perform an X-ray examination. The entire length on the injured bone must be visible because a fracture may be present at several spots. The bone also has to be shown in two projection views. Sometimes additional projections are necessary for clarification [24] [25] [29].

Two signs of fractures are to be considered. Reliable signs are crepitation between fragments, deformations and pathological mobility. Unreliable signs are swelling, pain and limited mobility of the affected part [23]-[25] [28].

\subsection{Treating Fractures}

Fractures can be treated 1) conservatively, with closed alignment and external immobilization, 2) surgically, where the fracture is aligned and internal immobilization performed to achieve the best possible anatomical position between segments and 3) functionally, where treatment does not involve immobilization or immobilization time is shortened. The objective of treatment is the best anatomical alignment of fragments and functional recovery achieved through alignment, keeping the fragments in the correct position and rehabilitation [25]-[27].

\subsection{Osteoporosis and Femoral Fractures}

Osteoporosis is a metabolic bone disease with typically deformed composition of bone tissue and decreased 
bone strength and mass to the degree of becoming fragile and breakable [30]. An osteoporotic bone differs from a normal bone in structure and content of bone minerals; bone trabeculae attenuate and disappear. Therefore only a minor external force is required for a fracture to occur. Osteoporotic fractures are three times more common in women and occur after the age of 50 . The most common are fractures of the radius in the wrist, vertebral fractures, fractures of the upper part of the humerus and femur [31]-[33].

Fractures of the femoral neck and bones of the trochanter are the most common and account for as nearly as half of all fractures in elderly people. Mortality associated with hip fractures is in the first years after the injury between $13 \%$ to $30 \%$; however, after years the survival rate is levelled with the remaining population for the same age group [34]-[36].

\section{Osteoporotic Fractures of the Femur}

Pertrochanteric fractures are fractures in the femoral area connecting minor and major trochanter. The area is well circulated because of the attachment of large muscles. Due to good vascular network, the possibility of non-union of fractures is very small [34] [37]. These types of fractures are the most common in elderly people. The average age of injured people is 75 years. In younger patients, they result from high-energy injuries [34][37]. 70\% of these fractures occur in women. Factors, affecting this ration, are larger tendency to osteoporosis and longer life expectancy than in men [35] [37] [38]. Kyle somewhat disagrees with this statement: the main cause for injuries is muscular weakness, paresis, instability due neurological diseases and osteoporosis is only a factor contributing to the injury [34].

The mechanism behind a pertrochanteric fracture is a fall on the hip, where a major force applied on the major trochanter, works simultaneously with the torsional force on the diaphyseal femur and the pull of the muscle iliopsoas on the small trochanter and the abductors on the major trochanter. At times the bone breaks due to severe osteoporosis when taking an awkward step and the fall results in a fracture [34] [39]. Due to osteoporotic changes in the bone tissue, comminuted fractures often occur [36] [38] [39].

When examining a patient with pertrochanteric fracture, the injured leg is shortened and rotated outwards, with the lateral margin of the foot almost touching the bed. Movement is completely disabled and painful. Among diagnostic procedures X-ray imaging is used in two projections to specifically define the type of fracture and distinguish between pertrochanteric and subcapital fracture [37] [40]-[42].

\subsection{Classification of Fractures}

The classification of pertrochanteric fractures enables the definition of fracture stability, which is the most important prognostic factor.

Fractures are categorized as stable and unstable, although not all physicians agree with this classification [37]. In stable fractures, the posteromedial pillar is not injured or minimally shifted and the fragments are stable. In unstable fractures a large segment of the posteromedial pillar with is comminutively broken with three or four fragments which are distanced from each other.

The classification by Evans and Boyd further classifies fractures into non-comminuted, fractures with minimal comminution and fractures with subtrochanteric components.

A modification of the Evans classification is the classification by Kyle and Gustilo, distinguishing between four types fractures: type 1 are not shifted, stable pertrochanteric fractures without comminution; type 2 are stable, minimally comminuted with shifted fragments (34\%), type 3 are unstable with posteromedial comminution (28\%). Type 4 fractures are pertrochanteric fractures with subtrochanteric components. These are rare (15\%), very unstable and difficult to treat [34] [36]-[38]. Another important classification is the AO (Arbeitsgruppe fuer Osteosynthesefragen) classification.

\subsection{Treating Pertrochanteric Fractures}

Treating pertrochanteric fractures is surgical and non-surgical [41]. The main objective it to achieve proper bone healing without rotational deformations, with normal length of the extremity and complete establishment of muscle strength and joint movement. Therefore in all pertrochanteric fractures, a precise repositioning (reduction) is required to decrease the level of pain, limitations of movement, traumatic arthritis and achieve optimal functional results. An oedema is common in fractures and frequently disables a proper repositioning [38] [39]. 
Successful treatment of pertrochanteric fractures depends on the stability of osteosynthesis, which is affected by level of osteoporosis, type of fixation and fracture [40]. Intramedular wires can be used, nails with a fixed plate, bolts and plates, attached with bolts to the bone [41]-[47]. An ideal implant needs to meet the following requirements: 1) low number of complications (surgical and infections); 2) the surgery has to be technically non-complicated, placement of implant quick and simple; 3) the implant has to be appropriate for several types of fractures and needs to enable early load applications [38].

\subsubsection{Stable Pertrochanteric Fractures}

Treatment of stable pertrochanteric fractures is simple, with small number of complications and uses any type of implant [38] [47]. According to Sauer et al., intramedullary osteosynthesis with a nail is biomechanically better than osteosynthesis with a plate [48]. The speed of recovery was not different according to a study performed by Baumgartner et al. [49]. The osteosynthetic plate is the most commonly used or 130-degree plate with nail [36].

\subsubsection{Non-Stable Pertrochanteric Fractures}

Non-stable fractures are more problematical because it is more difficult to achieve stability in such cases. Certain authors use longer and thicker metal plates whereas other intramedullary nails [36] [47] [50]. Regazzoni et al. used a dynamic hip screw (DHS), Ender's nails and angle osteosynthetic plates [38]. The use of fixed osteosynthetic plate is combined with valgisation osteotomy and medial shift of a part of diaphysis to prevent material fatigue. The procedure is technically demanding, the incision above the place of fracture large and the risk of infection increased. The functional results are not the best: the shift of the plate into the acetabulum is described, fracture of screw and plate due to material fatigue. The use of Ender's screws is technically simple, the surgery shorter and the loss of blood minimal. The main advantage is the absence of infections. Non-stable fractures cannot be stabilized firmly enough. Due to load applications the femoral neck can collapse, which leads to deformation and shift of screws into acetabulum, especially in short femoral necks and use of short screws [38] [46] [48]. DHS enables impaction of bone fragments in non-stable fractures and stable fixation. It is appropriate for all fracture types. Placement is simple, surgical time shorter than with a fixed plate, early load application is possible and infections are rarer [38] [51].

Hampton et al. [39] as well as Kristiansen et al. [40] recommend using a compression hip screw with a side plate. Bannister et al. do not support the use intramedular screws [47]; however, Ackroyd reports of the use of intramedular screws and consequent better stability [36]. Schatzker et al. use for type 1, 2, and 3 fractures DHS and for type 4 fractures a dynamic compression screw (DCS) with condillar plate and gamma screw, showing promising results [37]. DHS enables a solid fixation and stable fixation with a plate. Its impact on the bone healing, however, is not clear [52].

A new manner of non-stable fracture osteosynthesis is the percutaneous compression plate (PCCP). DHS may be the most commonly used, but it requires a long surgical incision [38] [53]. PCCP can be inserted with a minimally invasive technique, which decreases blood loss, devascularisation of bone fragments, post-operative complications and enables fast rehabilitations. Insertion is faster than with gamma screws and DHS and postoperative pain is smaller. PCCP can be removed percutaneously. There is no difference in the stability of osteosynthesis and bone healing when using PCCP or DHS [53]-[55].

\section{References}

[1] Turner, C.H. (2002) Biomechanics of Bone: Determinants of Skeletal Fragility and Bone Quality. Osteoporosis International, 13, 97-104. http://dx.doi.org/10.1007/s001980200000

[2] Winter, W. (2008) Bone Strength in Pure Bending: Bearing of Geometric and Material Properties. Studies in Health Technology and Informatics, 133, 230-237.

[3] Bouxsein, M.L. (2005) Determinants of Skeletal Fragility. Best Practice \& Research Clinical Rheumatology, 19, 897911. http://dx.doi.org/10.1016/j.berh.2005.07.004

[4] Bouxsein, M.L. and Karasik, D. (2006) Bone Geometry and Skeletal Fragility. Current Osteoporosis Reports, 4, 49-56. http://dx.doi.org/10.1007/s11914-006-0002-9

[5] Ulstrup, A.K. (2008) Biomechanical Concepts of Fracture Healing in Weight-Bearing Long Bones. Acta Orthopaedica Belgica, 74, 291-302.

[6] Butterwick, D., Papp, S., Gofton, W., Liew, A. and Beaulé, P.E. (2015) Acetabular Fractures in the Elderly, Evaluation 
and Management. Journal of Bone and Joint Surgery, 97, 758-768. http://dx.doi.org/10.2106/JBJS.N.01037

[7] Ascenzi, M.G., Gill, J. and Lomovtsev, A. (2008) Orientation of Collagen the Osteocyte Lacunae in Human Secondary Osteons. Journal of Biomechanics, 41, 3426-3435. http://dx.doi.org/10.1016/j.jbiomech.2008.09.010

[8] Augat, P. and Schorlemmer, S. (2006) The Role of Cortical Bone and Its Microstructure in Bone Strength. Age Ageing, 35, 27-31. http://dx.doi.org/10.1093/ageing/afl081

[9] Pidaparti, R.M. and Burr, D.B. (1992) Collagen Fiber Orientation and Geometry Effects on the Mechanical Properties of Secondary Osteons. Journal of Biomechanics, 25, 869-880. http://dx.doi.org/10.1016/0021-9290(92)90227-R

[10] van Oers, R.F., Ruimerman, R., van Rietbergen, B., Hilbers, P.A. and Huiskes, R. (2008) Relating Osteon Diameter to Strain. Bone, 43, 476-482. http://dx.doi.org/10.1016/j.bone.2008.05.015

[11] Szulc, P. (2006) Bone Density, Geometry, and Fracture in Elderly Men. Current Osteoporosis Reports, 4, 57-63. http://dx.doi.org/10.1007/s11914-006-0003-8

[12] Buller, L.T., Lawrie, C.M. and Vilella, F.E. (2015) A Growing Problem: Acetabular Fractures in the Elderly and the Combined Hip Procedure. Orthopedic Clinics of North America, 46, 215-225. http://dx.doi.org/10.1016/j.ocl.2014.11.009

[13] Silva, M.J. (2007) Biomechanics of Osteoporotic Fractures. Injury, 38, 69-76. http://dx.doi.org/10.1016/j.injury.2007.08.014

[14] Komadina, R. (2008) Hip, Osteoporosis: New Paradigm. European Journal of Trauma and Emergency Surgery, 2, 163-170. http://dx.doi.org/10.1007/s00068-007-7004-X

[15] Szulc, P., Munoz, F., Duboeuf, F., Merchant, F. and Delmas, P.D. (2006) Low Width of Tubular Bones Is Associated with Increased Risk of Fragility Fracture in Elderly Men-the MINOS Study. Bone, 38, 595-602. http://dx.doi.org/10.1016/j.bone.2005.09.004

[16] Cowin, S.C. and Mehrabadi, M.M. (1989) Identification of the Elastic Symmetry of Bone and Other Materials. Journal of Biomechanics, 22, 503-515. http://dx.doi.org/10.1016/0021-9290(89)90001-8

[17] Buckwalter, J.A. and Cooper, R.R. (1987) Bone Structure and Function. Instructional Course Lectures, 36, 27-48.

[18] Boskey, A.L. and Posner, A.S. (1984) Bone Structure, Composition, and Mineralization. Orthopedic Clinics of North America, 15, 597-612.

[19] Schoutens, A., Laurent, E. and Poortmans, J.R. (1989) Effects of Inactivity and Exercise on Bone. Sports Medicine, 7, 71-81. http://dx.doi.org/10.2165/00007256-198907020-00001

[20] Benjamin, M. and Ralphs, J.R. (2001) Entheses-The Bony Attachments of Tendons and Ligaments. Italian Journal of Anatomy and Embryology, 106, 151-157.

[21] Augat, P., Simon, U., Liedert, A. and Claes, L. (2005) Mechanics and Mechano-Biology of Fracture Healing in Normal and Osteoporotic Bone. Osteoporosis International, 16, 36-43. http://dx.doi.org/10.1007/s00198-004-1728-9

[22] Giannoudis, P., Tzioupis, C., Almalki, T. and Buckley, R. (2007) Fracture Healing in Osteoporotic Fractures: Is It Really Different? A Basic Science Perspective. Injury, 38, 90-99. http://dx.doi.org/10.1016/j.injury.2007.02.014

[23] Oryan, A., Monazzah, S. and Bigham-Sadegh, A. (2015) Bone Injury and Fracture Healing Biology. Biomedical and Environmental Sciences, 28, 57-71.

[24] Einhorn, T.A. (1998) The Cell and Molecular Biology of Fracture Healing. Clinical Orthopaedics and Related Research, 355, 7-21. http://dx.doi.org/10.1097/00003086-199810001-00003

[25] Tinubu, J. and Scalea, T.M. (2015) Management of Fractures in a Geriatric Surgical Patient. Surgical Clinics of North America, 95, 115-128. http://dx.doi.org/10.1016/j.suc.2014.09.017

[26] Burkhardt, M., Culemann, U., Seekamp, A. and Pohlemann, T. (2008) Strategies for Surgical Treatment of Multiple Trauma Including Pelvic Fracture. Review of the Literature. Der Unfallchirurg, 108, 812-820. http://dx.doi.org/10.1007/s00113-005-0997-x

[27] Donahue, S.W. and Galley, S.A. (2006) Microdamage in Bone: Implications for Fracture, Repair, Remodeling, and Adaptation. Critical Reviews in Biomedical Engineering, 34, 215-271. http://dx.doi.org/10.1615/CritRevBiomedEng.v34.i3.20

[28] Schatzker, J. (1996) Subcapital and Intertrochanteric Fractures. In: Schatzker, J. and Tile, M., Eds., The Rationale of Operative Fracture Care, Springer, Berlin-Heidelberg, 340-348. http://dx.doi.org/10.1007/978-3-642-88443-6_14

[29] Alonso, J.E., Lee, J. and Burger, A.R. (1986) The Management of Complex Orthopedic Injuries. In: Asensio, J.A., Demetriades, D. and Berne, T., Eds., The Surgical Clinics of North America, Saunders, 76, 879-903. http://dx.doi.org/10.1016/S0039-6109(05)70486-2

[30] Duquet, N. (2014) Osteoporosis: Risk Factors and Prevention. Journal de pharmacie de Belgique, 2, 4-12.

[31] Rincon-Kohli, L. and Zysset, P.K. (2008) Multy-Axial Mechanical Properties of Human Trabecular Bone. Biomechan- 
ics and Modeling in Mechanobiology, 8, 195-208. http://dx.doi.org/10.1007/s10237-008-0128-z

[32] Sinaki, M. (1998) Musculoskeletal Challenges of Osteoporosis. Aging, 10, 249-262. http://dx.doi.org/10.1007/bf03339659

[33] Benhamou, C.L. (2007) Effects of Osteoporosis Medications on Bone Quality. Joint Bone Spine, 74, 39-47. http://dx.doi.org/10.1016/j.jbspin.2006.06.004

[34] Kyle, R.F. (1991) Intertrochanteric Fractures. In: Steinberg, M.E., Ed., The Hip and Its Disorders, Saunders, Philadelphia, 280-290.

[35] Bonnaire, F., Straßberger, C., Kieb, M. and Bula, P. (2012) Osteoporotic Fractures of the Proximal Femur. What's New? Der Chirurg, 83, 882-891. http://dx.doi.org/10.1007/s00104-012-2340-8

[36] Ackroyd, C.E. (1979) Pertrochanteric Fractures of the Femur. In: Bentley, G., Ed., Operative Surgery, Orthopaedics, Part 1, Butterworth \& Company, Boston, 120-125.

[37] Legroux, G.I., Demondion, X., Louville, A.B., Delcambre, B. and Cortet, B. (2004) Subchondral Fractures of the Femoral Head: A Review of Seven Cases. Joint Bone Spine, 71, 131-135.

[38] Regazzoni, P., Rueedi, T.H., Winquist, R. and Allgoewer, M. (1985) The Dinamic Hip Screw Implant System. Springer Verlag, Berlin. http://dx.doi.org/10.1007/978-3-642-69925-2

[39] Hampton, O.P. and Fitts, W.T. (1957) Fratctures and Dislocations of the Lower Extremity. In: Allen, J.G., Harkins, H.N., Moger, C.A., Rhoads, J.E. and Lippincot, J.B., Eds., Surgery, Principles and Practice, Lippincot Company, Philadelphia, 327-328.

[40] Kristiansen, T.K. and Hansen, S.T. (1987) Fractures. In: Davies, J.H., Ed., Clinical Surgery, Mosby, St. Louis, 29953001.

[41] Cascone, R., Lieberman, B. and Deitz, S. (1996) Courtroom Medicine. In: Kalisch, J.R. and Williams, H., Eds., Hip and Thigh, Matthew Bender.

[42] Reimer, B.L., Foglesong, M.E. and Miranda, M.A. (1994) Femoral Plating. Orthopedic Clinics of North America, 25, 625-633.

[43] Kregor, P.J., Obremskey, W.T., Kreder, H.J. and Swiontkowski, M.F. (2014) Unstable Pertrochanteric Femoral Fractures. Journal of Orthopaedic Trauma, 28, 25-28. http://dx.doi.org/10.1097/BOT.0000000000000187

[44] Mueller, M.E., Allgoewer, M., Schneider, R. and Wilengger, H. (1992) Manual of Internal Fixation. 519-534.

[45] Mueller, M.E. and Nazarian, S. (1981) Classification et documentation AO des fractures du fémur. Revue de Chirurgie Orthopedique, 67, 297-309.

[46] Roberts, J.M. (1991) Extracapsular Fractures. In: Steinberg, M.E., Ed., The Hip and Its Disorders, Saunders, Philadelphia, 160-165.

[47] Bannister, G.C., Ackroyd, C.E. and Langkamer, V.G. (1991) Trochanteric Fractures of the Femur. In: Bentley, G. and Greer, R.B., Eds., Rob \& Smith’s Operative Surgery, Orthopaedics, Part 1, Butterworth-Heinemann, London, 209-215.

[48] Sauer, H.D., Schottle, H. and Jungbluth, K.H. (1977) Dynamic Force Resistance of Different Osteosynthetic Rocedures in Pertrochanteric Femoral Fractures. Archiv für orthopädische und Unfall-Chirurgie, mit besonderer Berücksichtigung der Frakturenlehre und der orthopädisch-chirurgischen Technik, 89, 275-282. http://dx.doi.org/10.1007/BF00416955

[49] Baumgaertner, M.R., Curtin, S.L. and Lindskog, D.M. (1998) Intramedullary versus Extramedullary Fixation for the Treatment of Intertrochanteric Hip Fractures. Clinical Orthopaedics, 348, 87-94. http://dx.doi.org/10.1097/00003086-199803000-00015

[50] Fagagnolo, F., Kfuri, M. and Paccola, C.A. (2004) Intramedullary Fixation of Pertrochanteric Hip Fractures with the Short AO-ASIF Proximal Femoral Nail. Archives of Orthopaedic and Trauma Surgery, 124, 31-37. http://dx.doi.org/10.1007/s00402-003-0586-9

[51] Geissler, N., Meffert, O., Stapel, A. and Heymann, H. (1994) Results of Surgical Management of Unstable Pertrochanteric Femoral Fractures with the Dynamic Hip Screw and T-Plate. Unfallchirurgie, 20, 184. http://dx.doi.org/10.1007/BF02588168

[52] McLaren, C.A.N., Buckley, J.R. and Rowley, D.I. (1991) Intertrochanteric Fractures of the Femur: A Randomized Prospective Trial Comparing the Pugh Nail with the Dynamic Hip Screw. Injury, 22, 193-195. http://dx.doi.org/10.1016/0020-1383(91)90039-H

[53] Brandt, S.E., Lefever, S., Janzing, H.M., Broos, P.L., Pilot, P. and Houben, B.J. (2002) Percutaneous Compression Plating (PCCP) versus the Dynamic Hip Screw for Pertrochanteric Hip Fractures: Preliminary Results. Injury, 33, 413418. http://dx.doi.org/10.1016/S0020-1383(02)00080-3

[54] Janzig, H.M., Houben, B.J., Brandt, S.E., Chhoeurn, V., Lefever, S., Broos, P., et al. (2002) The Gottfried Percutaneous Compression Plate versus the Dynamic Hip Screw in the Treatment of Pertrochanteric Hip Fractures: Minimal In- 
vasive Treatment Reduces Operative Time and Postoperative Pain. Journal of Trauma, 52, 293-298. http://dx.doi.org/10.1097/00005373-200202000-00015

[55] Kosygan, K.P., Mohan, R. and Newman, R.J. (2002) The Gottfried Percutaneous Compression Plate Compared with the Conventional Classic Hip Screw for the Fixation of Intertrochanteric Fractures of the Hip. Journal of Bone and Joint Surgery, 84, 19-20. http://dx.doi.org/10.1302/0301-620X.84B1.11919 